Contract No. w-7405, eng 26

\title{
MATHEMATICS PANEL.
}

\section{QUARTERLY PROGRESS REPORT}

\section{for Period Ending January 31, 1952}

A. S. Householder, Chief

\begin{abstract}
EDI TED BY:
\end{abstract}
C. L. Perry

DATE ISSUED

\section{APR 251952}

OAK RIDGE NATIONAL LABORATORY

operated by

CaRbide and CaRBon ChEMICALS COMPANY

A Division of Union Carbide and Carbon Corporation

Post office Box P

Oak Ringe, Tennessee

Photostat Price s_ 4.80
Microfilm Price s_2.70
Available from the
Office of Technical Services
Deportment of Commerce
Washington 25, D. C.


Mathematice Panel quarterly progrese reporte previously iseued in this sories - of followa:

$\begin{array}{ll}\text { ORNL-345 } & \text { December, January, February, } 1940 \\ \text { ORNL-408 } & \text { Period Ending July 31, } 1949 \\ \text { ORNL-516 } & \text { Period Ending October 31, } 1949 \\ \text { ORNL-634 } & \text { Period Ending January 31, } 1950 \\ \text { ORNL-726 } & \text { Period Ending April 30, } 1950 \\ \text { ORNL-818 } & \text { Period Ending July 31, 1950 } \\ \text { ORWL-888 } & \text { Period Ending October 31, } 1950 \\ \text { ORNL-979 } & \text { Period Ending January 31, } 1951 \\ \text { ORNL-1029 } & \text { Period Ending April 30, 1951 } \\ \text { ORNL-1091 } & \text { Period Ending July 31, 1951 } \\ \text { ORNL-1151 } & \text { Period Ending October 31, } 1951\end{array}$


Preparation and Analysis of Subroutines for the Digital Conputer

Basic Studies in the Monte Carlo Method

Methods of Computation for Use with a High-speed Automatic-

Sequenced Computer.

Expected Value of Reliability of a Test

Analysis of Temperature Effects on Haploid and Diploid Forms of Saccharonyces Cerevisiae Exposed to X-Radiation

Estimation of Variance Components in a Sterility Experiment with Mice

Analysis of Recombination Percentages for Several Experiments with Bacteriophege $\mathrm{T} 2 \mathrm{H}$

Determination of a Probability Distribution for a Genetics Experiment, 13

Irradiation Effect on Cell Extinction 14

A Problem in Mixing

Kinetics of the $\mathrm{HBrO}_{3}$ Reaction

Ion Production in an. Ionization Chamber

Evaluation of the Lateral Distribution of Energy Dissipated by a Moving Ion.

Monte Carlo Estimate of Collision Distributions in Tissue,

Amp.lifier Response to Proportional Counter Pulses.

$X$-Ray Crystal Anal ysis

Fermi Functions.

Calculation of Internal Conversion Coefficients with Screening

Calculation of Racah Coefficients for the Angular Distribution in Nuclear Reactions

Beta Decay (Field Factórs)

Estimation of Error and Counting Periods in Pile Experiment

Calibration of Calorimeter. 


\section{PROJECTS}

Determination of Fast Neutron Flux in X-10 Graphite Pile

Kinetics of HRE

Circulation in Boiling Reactors

Investigation of Solutions of the Boltzmann Equation for the Diffusion of Neutrons

A Multigroup Method for Computing the Neutron Distribution in a

Cylindrical Reactor with Reflected Convex Surface and Bare Ends

Kinetics of Intermediate and Large Homogeneous Reactors

PENDING PROBLEMS 


\section{MATHEMATICS PANEL QUARTERLY PROQRESS REPORT}

\section{SUMMARY}

New additions to the Mathematics Panel this quarter are Virginia C. Carlock, Alabama Polytechnic Institute; and Elizabeth N. Lawson, Florence (Alabama) State Teachers College. Also, V. A. Hoyle, University of North Carolina, is spending the winter quarter as Research Participant with the Panel.

The course on the preparation of problems for an automatic digital computer was held as planned during the first two weeks of December ( $\mathrm{cf}$. the previous quarterly progress report, ORNL-1151). Seventeen persons were registered for the course, some from colleges and some from industrial laboratories. More than hundred auditors were present for the opening lecture by Prof. John von Neumann, Institute for Advanced Study, and thereafter the attendance at the lectures remained fairly constant at figures above fifty.

The principal lecturer was D. A. Flanders, Argonne National Laboratory, who gave a series of lectures on the arithmetic operations of the machine, the basic operations, the flow chart, and the design of programs. Professor von Neumann's lecture was entitled "Some General Principles on the Balance of Characteristics of High-Speed Computing Machines." A. H. Taub and J. P. Nash, University of Illinois, lectured on general principles of programming and on the logical design of the computer, respectively. (As they spoke the ORDVAC was successfully undergoing acceptance tests at the University of Illinois.) C. V. L. Smith, Office of Naval Research, gave a comparative survey of digital computers.
Mathesetics Panel speakers were C. L. Perry, on subroutines; J. W. Givens, on matrix computations; N. M. Di-vuke, on Tebebycheff polynomials an the representation of functions: B. M. Drucker, on system of nonlinear differential equations conputed on the SEAC; and A. S. Householder, on the solution of lgebraic and transcendental equations.

Except for minor variations in schedule, the afternoons were devoted to practice sessions in coding for such problems as extracting square roots, the evaluation of trigonometric functions, and autiple precision computations.

Fabrication of the Oak Ridge computer is under way ot Argonne National Laboratory and at the Technitrol Company, but the work has been retarded somewhat by procurement difficulties. The arithmetic frame has been completed at Argonne; the A and $Q$ registers have been fabricated and shipped by Technitrol: the $S$ register is partially finished; the adder is being constructed. The clear and transfer drivers and the shift counters have been designed.

Further work is being done to improve the memory system. The problem of "read-around" seems to be essentially solved with the discovery of an efficient tube, the 3BP1: J. R. Klein (ORNL) and B. Norris (ANL) reported on this work at the symposium on the Williams tube held at the Bureau of Standards in Washington. The difficulties caused by impurities in the phosphor of the memory system are now being studied. 


\section{mathEMATICS PANEL QUARTERLY PROGRESS REPOAT}

The list of basic operations to be built into the machine is now fixed, and thus it has been possible to begin the actual coding of problems. Standard subroutines ore being prepared, long wi th detailed and precise error analyses, to be included in a permanent library. They are construeted in such - way that they can be included in orbitrary special routines as automatically as possible. The subroutines -ill include computation of elementary. trigonometrie, logarithmic, rational power functions, and the like; multiple precision operatioas: roots of equetions: matrix operations; and integrations: and other computations of conmon occurrence. The library being prepared cen contribute greatly to the verastility of the nachine and to the speed wich which opeciel problems can be coded. Coding groups have been organized for this project, wich will be continuing one, and each group is responsible for the preporotion, analysis, and checking of elass of routines. The coding sessions follow the weekly seminars. W. Givehs has resumed his series of lectures on the fundamental peper on the inversion of matrices by von Neumann and Goldstine. These lectures were begun in the fall but were interrupted by the course.

Two large computing projects were completed during the quarter: (1) the calculation of the Fermi functions, - (to be issued as an ORNI report), and (2) the Monte Carlo estimate of the collision distribution in tissue for normally incident beams of colli. mated neutrons of high energy. The neutron histories for problem 2 will be saved for possible use in other problems.

Panel members presented the follow. ing lectures as a part of the OAINS Traveling Lecture Program:

\section{A. S. Householder}

"Matrices," Alabama Polytechnic Insti tute. January 18, 1952.

\section{A. M. Kimball}

"Statistical Design and Analysis of Experiments," Washington University. St. Louis, January 30, 1952.

\section{L. Perry}

"Programing for Automatic Computing Machines," Universicy of North Caro. lina. Novenber 28, 1951.

In addition, the following papers were presented or published during the querter:

\section{J. Moohean}

"Teoting Two-wey Cleasificetion Uoing the Ronge," presented ot the Anericon Statistical Aosociotion and the Bionetrice Society in Boston, 1951.

"A Simple Procedure for Deternination of the Approximate lymph Spoce," published in Vol. 114 of Seience.

\section{A. S. Householder}

"Polynomial Iterotions to Roots of Algebraic Equations," published in the Proceedings of the Anerican Watheatieal Society, Vol. 2, No. 5, 718-719 (1951).

\section{A. ". Kimball}

"On Dependent Tests of Signi ficance in the Analysis of Variance," published in Vol. 22 of the Annals of Watheatical Statistics.

\section{w. Givens}

"Field of Values of Matrix," pre. sented at the American Mathematical Society meeting in Auburn, Alabama. 
PERIOD ENDING JANUARY 31, 1952

\section{UNCLASSIFIED PROJECTS}

PREPARATION AND ANALYsis of seBeovtines ven taE digital. conputea

seanary. The basic machine operotions and expected speeds are as follows:

1. Sumation, eight distinct operations for adding or subtracting the numbers of magnitude with or without prior elearing of the accumblator. So $\mu \mathrm{ss}$.

2. Shift, eight distinet right shifts and eight left shifts on arbitrary number of times up to 48 . In nonzero shifts the A register Iways shifts and the Q register may or may not shift. $10 \mu \mathrm{s}$ plus $20 \mathrm{\mu s}$ for each set of four or less.

3. Multiplication, with or without the addition of $2^{* 40}$ for roundoff. A minimus of 210 us and seaximen of $410 \mathrm{\mu s}$.

4. Division, with or without the arbitrary insertion of anit in the last place to remove the biased round. off and with either a single- or a double-precision dividend. $410 \mathrm{\mu s}$.

5. Memory to Q, oingle order. $50 \mu \mathrm{s}$.

6. Substitution, total or partial transfer of the costents of $A$ or $Q$ into opecified memory position. In - partial substitution the first, second, third, and fourth sets of ten consecutive digits from a given register can be transferred independently, any one or more sets without the others, or even none at all. $50 \mathrm{\mu s}$.

7. Transfer of control, unconditional or conditional. If con ditional, the transfer of control is dependent upon the sign of the contents of the $A$ regieter, or upon the occurrence or nonoceurrence of over. flow. 30 hs.

\section{Stop.}

The subroutines, in effect, extend the list of basic operations, al though at the expense of sose storage space in the mesory. For example, if a computation requires the extraction of square roots and a square-rooting subroutine has been prepared, then this will be inserted once in the nais routine. Therefore, when the computation requires: square root, the radicand oill be transferred to a fixed location in the menory, an "exit order" placed to show where the main routine is to be picked up again. and the control sent to the subroutine. Thereupon the root will be extracted and placed in a fixed location in the memory and the control transferred back to the main routine by the exit order. This operation can be repeated any number of $t i m e s$ in the course of the entire computation, and thus any number of square roots can be extracted -ith only a single insertion of the routine itself. It is only necessary that the main routine provide for the insertion of the radicand and the removal of the previous root before each use. In like wanner, routines for multiple precision and others for floating decimal operations, can be prepared once and for all. As a somewhat more elaborate example, a single routine can be prepared for solving a systen of linear algebraic equations of arbitrary order by inserting the order as one of the parameters.

Usually there are more ways than one of carrying out a particular computation, and three factors enter into the selection of any particular 


\section{MATHEMATICS PANEL QUARTERLY PROGRESS REPORT}

method. These are the space, or the number of words occupied in the memory by the routine; time, or the length of time required for the machine to go through the computation; and precision, or the effect of roundoff. A proposed routine wight compare favorably with onother on one criterion and unfavorably on some other criterion, and the extent to which a given factor is critical vill depend upon the over-all probles in hasd. Consequently if no single routine oppeors optimal on all factors, different routines may be needed in the library. For each routine, the error limits must be ascertained as precisely as pozsible. Thas, for $\sqrt{a},$. where a is given to 39 binary digits, one can orrive by Nevton's sethod at number $x$, satis fying

$$
-2 * 40<x-\sqrt{a+2-00} \leqq 2 * 00 .
$$

This is ochieved by a routine of eight words, which requires three auxiliary storage positions and takes a maximus of $36.02=s$. If it is not thought necessary to test the sign of a to make sure the computation will be meaningful. Incidentally the process yields $x=2.30$ when $a=0$. If, as a precaution. it is desired that the achine stop or take remedial steps should a turn out to be given as a negative number and yield $x=0$ when $a=0$, then 11 words are necessary and the time is 36.24 ms. By a doubleprecision computation, if a is given to 78 binary digits, it is possible to obtain s accurately to 76 binary places with 21 additional words and an extra operating time of $2.72 \mathrm{~ms}$.

The floating decimal arithmetical operations have been coded at Argonne, but they require final checking and error analysis. Multiple-precision arithmetic operations including squarerooting are nearly complete. Boutines for single-precision square-rooting, obtaining sines and cosines, evaluation of a polynomial of arbitrary degree and for an arbitrary number of values of the argument, and transformation of variables in a polynomial are es sentially complete witherror analyois. Routines are being prepared for other el ementary functions, including rational powers: for operations with cosplex numbers; for numerical integration and interpolation; for certain statistical computations; and for certain operations with matrices and vectors.

\section{Basic studies IN THE monte caRLo method}

\section{Participatiag weober of Panel.} G. E. Albert.

geferences. (1) G. E. Albert, "Basic Studies in the Monte Carlo Method," Matheaatics Panel Quarterly Progress Reports for the Periods Ending July 31, 1951, and Oetober 31. 1951, ORNL-1091 and ORNI-1151. (2) G. E. Albert, Memorandums to A. S. Howseholder on "A General Approach to the Monte Carlo Estimation of the Solutions of Certain Fredholm Integral Equations," Parts 1, II, and 11I.

Background and status. As explained in reference (1). Parts I and II of reference (2) contain mathematical exposition of the theory underlying various statistical techniaues that have been used in computing centers over the country for the estimation of solutions of certain types of integral equations and the estimation of weighted integrals of such solutions. In addition. Part II of reference (2) contains an innovation, created by the participant, in the introduction of a certain type of simple stratified sampling into these estimation problems.

Part III of reference (2), issued during this quarter, describes a continued study of the use of stratified 
sampling begun in Part II and gives special consideration to the possibilities of designing estimation procedures to make efficient use of the advantages of high-speed automatic computing wachinery. Specifically, Part II contains descriptions of sample spaces and probability distri. butions in which repeated sampling for chains of fixed length and stratified sampling for both chain lengths and chain points may be used. Suggestions are made for the chioice of probability distributions that are simple enough so that complex sampling methods might be practical on high-speed machinery, -ith which efficiency is gained by computing methods that isvolve many repetitions of simple operations.

The participant proposes to continue this project in two ways. First, applications of the techniques suggested in reference (2) to specific iategral equations should be tried. Second, the estimation techniques proposed give estimates of the solution of an integral equation at a.single point. Application of any technique to the estimation of the values of the solution at many poinch, either through independent or correlated samples, would lead to a discrete random series. Smoothing and interpolation for such a series will be studied at some length.

\section{mETHODS OF CeMPUTATION FOR USÉ DITU A HIGH-SPEED AUTOWATIC-SEQUENCED COW- PUTER}

Participating weaber of Panel. w. Givens.

Beference. Natheatics Panel Quarterly Progress Report, ORNL-1151.

Problea 2. Nueerical Inverting of matrices of uigh order.

status. After an interruption for the Computer Course in December and some reports on coding. lectures on the von Neumann-Goldstine pape:s are being continued before the Mathematics Panel Seminar. When it is necessary, the error estimates are being modified to make them applicable to the Oak Ridge computer. Work on this probiem will be continued.

Problea 3. Nuserical Coaputation of Eigenvalues and Eigenvectors.

status. The method deacribed in the last quarterly report is being studied for the effect of roundoff error on the aceuracy of the computation. The work of Lidskii(1) permits more efficient estimates by allowing one to replace the sum of squares of the eigenvalues. An upper bound for the maximum eigenvalue of a symmetric (error) matrix with two nonzero rows and columns has been found in terms of those bounds for the elements that are appropriate for the computation under study. Error bounds given by Goldstine for his proposed solution of this problem have been studied in a manu. seript obtained from him. This work is to be continued.

\section{EXPECTES VALUE OF RELIABILITY OF A TEST}

Participating weaber of Panel. J. Moshman.

Background and status. Let $y$ be a measured value of some true parameter $\boldsymbol{x}$. It is assumed thiat

$$
y=x+\epsilon .
$$

where $\epsilon$ is some error term uncorrelated with $x$, and that $x$ and $\epsilon$ are each normally distributed with means $\mu$ and

(1)v. B. Lidakib, "Eigenval aes of the Sems and Prodect. of Symaetricei Wotrixes" (trosoloted), Dokled. Aled. Wsat. Sssh 75. 769-772 (1950). 


\section{mateismatics PANEL QUARTERI.I PROGRESS REPORT}

0 and variances $\sigma^{2}$ and $\sigma_{\epsilon}^{2}$, respectively. The reliability of the mensure $y$ is defined as

$$
P=\frac{\sigma_{z}^{2}}{\sigma_{y}^{2}}=\frac{\sigma_{z}^{2}}{\sigma_{z}^{2}+\sigma_{z}^{2}}=\frac{1}{1+\zeta} .
$$

where P (capital rho) is the reliability and $\zeta=\sigma_{a}{ }^{2} / \sigma_{n}{ }^{2}$. and

$$
f_{2}\left(s_{x}^{2}\right)=K_{2}\left(s_{x}^{2}\right)^{(a / 2)-1} \exp \left[\frac{--s_{z}^{2}}{2 \sigma_{z}^{2}}\right]
$$

are the respective probability density functions of $s_{s^{2}}$ and $s_{z}^{2}$, where $K_{1}$ and $K_{2}$ are appropriate normalizing constants. The distribution of $z$ is then $(2)$

$$
\begin{aligned}
& f(z)=\int_{0}^{\infty} s_{z}^{2} f_{1}\left(z s_{z}^{2}\right) f_{2}\left(s_{z}^{2}\right) d s_{z}^{2}
\end{aligned}
$$

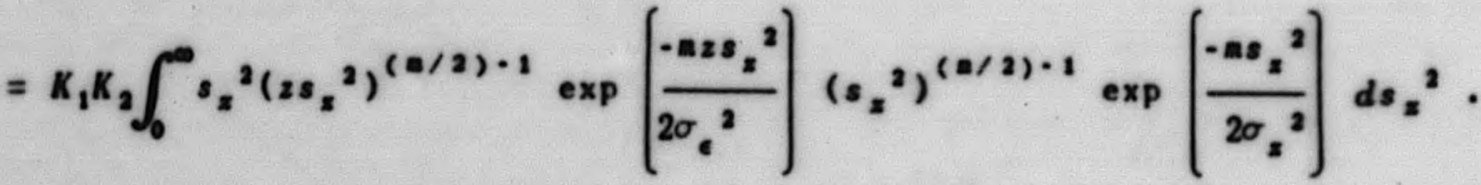

If $\sigma_{g}{ }^{2}$ and $\sigma_{e}{ }^{2}$ can be estimated by $s^{2}$ and $s^{2}$, the usual root-meansquare sample estimate, the expected value of

$$
R=\frac{1}{1+z}
$$

where

$$
z=\frac{s_{e^{2}}^{2}}{s^{2}}
$$

can be determined and sone concept gained of any existing bias.

It is we!l known that $s_{e}^{2}$ and $s_{s}^{2}$ each have a $\chi^{2}$ distribution with, say, a degrees of freedom. That is,

$$
f_{1}\left(s_{\epsilon}^{2}\right)=K_{1}\left(s_{\epsilon}^{2}\right)^{(\theta / 2)-1} \exp \left(\frac{-m s_{e}^{2}}{2 \sigma_{\epsilon}^{2}}\right)
$$

After some reduction,

$$
f(z)=K_{z}(\bullet / 2) \cdot 1(z+\zeta)^{-a} .
$$

To determine $K$, the following condition is imposed:

$\int_{0}^{\infty} f(z) d z=K \int_{0}^{\infty} z(-/ 2)-1(z+\zeta)^{-\infty} d z=0$

and it is found that

$$
K=\frac{\zeta^{\infty / 2}}{B\left(\frac{\mathrm{a}}{2}, \frac{\mathrm{a}}{2}\right)} \text {. }
$$

where

$B(r, s)=\frac{\Gamma(r) \Gamma(s)}{\Gamma(r+s)}=\frac{(r-1) !(s-1) !}{(r+s-1) !}$.

(2) Wu. 6. Xeadoll, The Advanced Theory of stotioties, 24 ed., rev, Griffis, Loodos, igis. 
To find $\epsilon(R)$, the expected value of $R, 30,000$ and $120,000 \mathrm{r}$, respectively, of $\epsilon(R)=\int_{0}^{\infty} R f(z) d z$

$$
=\frac{\zeta^{\infty / 2}}{B\left[\frac{m}{2^{\prime}} \frac{a}{2}\right]^{\infty}} \int_{0}^{\infty} \frac{z(\theta / 2) \cdot 1}{(1+z)(\zeta+z)^{n}} d z .
$$
$x$ radiation at three temperatures. An equal number of controls were run at each temperature. The problem was to determine whether temperature affects the ability of the organisms to survive after exposure to radiation.

Four independent counts were obtained for both types of organisms

After considerable calculation, at each temperature in both the con-

$\epsilon(R)=\frac{\zeta^{n+1}}{B(n+1, n+1)}\left\{\frac{(-1)^{n}}{(1-\zeta)^{n}} \ln \xi+\sum_{k=0}^{n-2} \frac{\sum_{i=0}^{k}\left(\begin{array}{l}k \\ i\end{array}\right) \prod_{j=0}^{k} \frac{n-j}{n-i}(-\zeta)^{n-i}}{k !(1-\zeta)^{k+1}(n-k-1) \zeta^{\infty-k+1}}\right\}$.

where $n=(n / 2)-1$.

Some sample hand calculations were made for $\zeta=0.2$ and $n=4,6$, and 8 . The true value, $P$, is 0.833 and $\epsilon(R)=0.787,0.802$, and 0.812 , respectively. $R$ is a biased estimate of $P$, but it is conjectured that for large $m$, the order of magnitude used in most practical applications, the bias is negligible. It is planned to employ automatic calculating machines to investigate further the behavior of $\epsilon(R)$ for various combinations of $\zeta$ and large values of $\mathbf{a}$.

\section{ANALYSIS OF TEMPERATURE EFFECTS ON} HAPLOID AND DIPLOID FORHS OF SACCHAROMYCES CEREVISIAE EXPOSED TO X RADIATION

origin. S. Pomper, Biology Division.

Participating weobers of Panel. A. W. Kimball and G. J. Atta.

Background and status. Haploid and diploid forms of the yeast Saccharomyces cerevisiae were exposed to trol and the treated groups. The means are shown in Table 1 . Control counts are expressed in $10^{\circ}$ units, and treated counts are expressed in $10^{5}$ units.

TABLE 1

Averace Counts

\begin{tabular}{c|r|r|r}
\hline & \multicolumn{3}{|c}{ TEPERATURE } \\
\cline { 2 - 4 } & $30^{\circ} \mathrm{C}$ & \multicolumn{1}{|c}{$18^{\circ} \mathrm{C}$} & \multicolumn{1}{c}{$12^{\circ} \mathrm{C}$} \\
\hline $\begin{array}{l}\text { Heploid } \\
\text { Control. }\end{array}$ & 152.3 & 145.2 & 145.0 \\
Treated & 30.0 & 25.5 & 20.7 \\
\hline Diploid & & & \\
Control. & 100.4 & 103.8 & 100.2 \\
Treated & 134.1 & 162.0 & 156.2 \\
\hline
\end{tabular}

The analyses in Table 2 were computed for the controls.

It is clear that temperature has no appreciable effect on survival among the control organisms. In view of this result, analyses for the treated organisms could be computed without 


\section{MATHEMATICS PANEL QUARTERLY PROGRESS REPORT}

correcting for a temperature effect among the controls. These analyses are shown in Table 3 .

\section{TABLE 2}

Analysees of Veriance

(beeed on equare roote)

\begin{tabular}{c|c|c|c}
\hline \multirow{2}{*}{$\begin{array}{c}\text { SOURCE of } \\
\text { VARIATION }\end{array}$} & $\begin{array}{c}\text { DEGREES OF } \\
\text { FREEDOM }\end{array}$ & \multicolumn{2}{|c}{ MEAN SQUARE } \\
\cline { 3 - 4 } & HAPLOIDS & DIPLOIDS \\
\hline $\begin{array}{c}\text { Among tee- } \\
\text { peratures }\end{array}$ & 2 & 0.1181 & 0.0397 \\
$\begin{array}{c}\text { Within te- } \\
\text { peratures } \\
\text { Total }\end{array}$ & 9 & 0.3307 & 0.2762 \\
\hline
\end{tabular}

TABLE 3

Analyses of Variance

(based on square roots)

\begin{tabular}{c|c|c|c}
\hline \multirow{2}{*}{$\begin{array}{c}\text { SOURCE OF } \\
\text { VARIATION }\end{array}$} & \multirow{2}{*}{$\begin{array}{c}\text { DECREES OF } \\
\text { FREEDOM }\end{array}$} & \multicolumn{2}{|c}{ MEAN SQUARE } \\
\cline { 3 - 4 } & HAPLOIDS & DIPLOIDS \\
\hline $\begin{array}{c}\text { Anong tem } \\
\text { peratures }\end{array}$ & 2 & 0.8570 & 1.4812 \\
$\begin{array}{c}\text { Within tee } \\
\text { peratures }\end{array}$ & 9 & 0.03080 & 0.6770 \\
\hline
\end{tabular}

A definite temperature effect is indicated in the haploid organisms, but the differences among the diploid means are not large enough to be statistically significant. There seems to be some indication that haploids and diploids react in opposite ways to changes in temperature, but in this experiment excessive variability among the diploid counts (a standard error almost five times as great as for the haploids) makes it impossible to draw definite conclusion.
ESTIAATION OF VARIANCE COMPONENTS IN A STERILITY EXPERIMENT EITH Mies

orisin. Louis Wickham, Biology Division.

Participeting neabere of Penel. A. W. Kimball and G. J. Atte.

Background and status. As part of the analysis of the experiment described in detail in ORNL-1167, (2) components of variance estimates were computed. From each of several lines of mice, several males were selected and each male was mated to four different females. Several litters were obtained from each female. This was done with semisterile males and with fertile males. As a mathematical model, it was assumed that the litter size for the ath line is

$$
x_{i j h k}=\mu+a_{i}+\beta_{i j}+\gamma_{i j k}+\epsilon_{i j k=} .
$$

where

$$
\begin{aligned}
& i=1, \ldots, r, \\
& j=1, \ldots, s_{i}, \\
& k=1, \ldots, t_{i j}, \\
& n=1, \ldots, n_{i j k},
\end{aligned}
$$

and

$$
\begin{aligned}
a_{i} & \sim N\left(0, \sigma_{a}{ }^{2}\right), \\
\beta_{i j} & \sim N\left(0, \sigma_{\beta}^{2}\right), \\
\gamma_{i j k} & \sim N\left(0, \sigma_{\gamma}{ }^{2}\right) . \\
\epsilon_{i j k l} & \sim N\left(0, \sigma^{2}\right) .
\end{aligned}
$$

This notation is conventional for indicating a random variable having

(3) A. A. Boleeey, The Preperation of Thin and of Thich Torgets to be Bobberded by Poitite

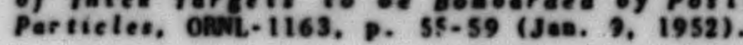


TABas 4

Analgees of variance

\begin{tabular}{|c|c|c|}
\hline somace of werurrar & 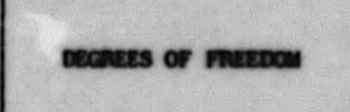 & 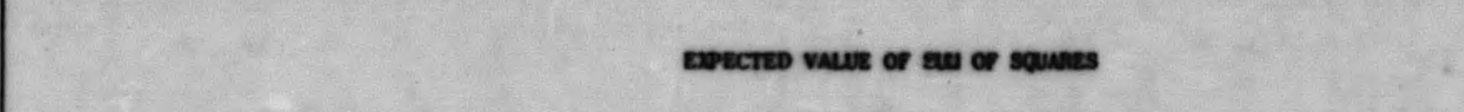 \\
\hline Anoose lines: & $(1 \cdot-1)$ & 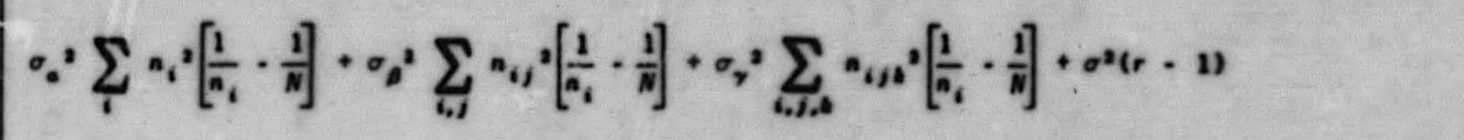 \\
\hline 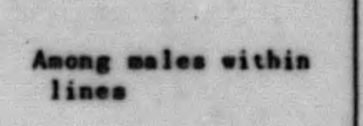 & $\left.\sum_{i=1} w_{i} \cdot 1\right)$ & 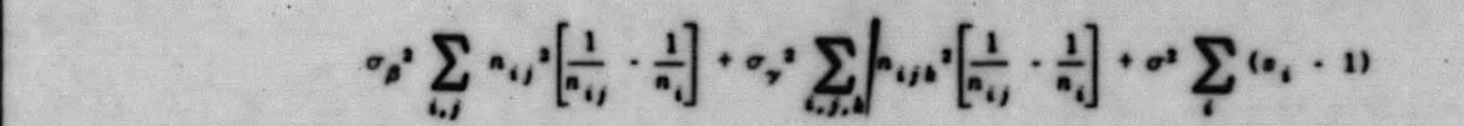 \\
\hline 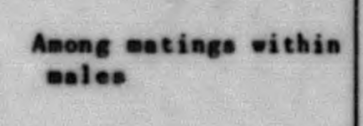 & $\sum_{i=1}^{1} \sum_{j=1}^{n}\left(u_{i, j}, \cdots\right.$ & 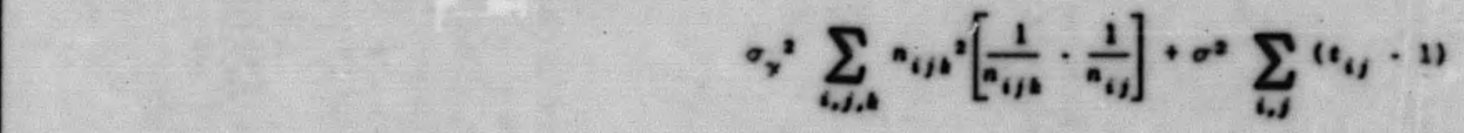 \\
\hline 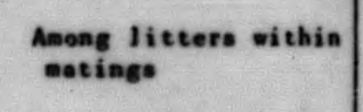 & $\sum_{i=1} \sum_{j=1}^{n} \sum_{i=1}^{n}\left(w_{0,1} \cdot 1\right)$ & 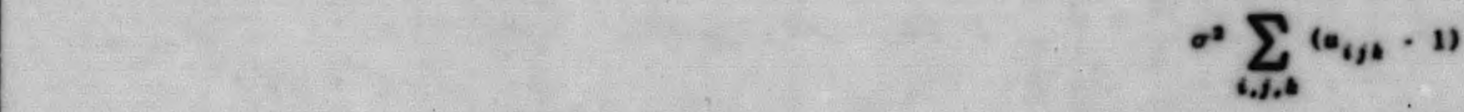 \\
\hline
\end{tabular}


a normal distribution with a specified mean and variance. It is al iso assumed that all of the $a_{i}, \beta_{i j}, \gamma_{i j k}$, und Cijhe are mutually independent. With this model it can be shown that the analysis of variance in Table 4 has expected sums of squares as indicated. As before, n $n_{i k}$ is the number of licters from the kth female mated to the $j$ th wale from the ith line, and

$$
\begin{aligned}
n_{i j} & =\sum_{i j k}, \\
n_{i} & =\sum_{j} n_{i j} . \\
N & =\sum_{i} n_{i} .
\end{aligned}
$$

In any experimental situation these expected values may be used to obtain estimates of $\sigma^{2}, \sigma_{\gamma}{ }^{2}, \sigma_{\beta}{ }^{2}$, and $\sigma_{a}{ }^{2}$ by a tepwise method of computation starting with the last sum of squares in the analysis of variance table.

In the wice data, the analyses were based on litter sizes and were performed separately on fertile and semisterile animals. The results are shown in Table 5.

Apart from the variation in litter sizes among litters from the same mating, only one component seems to contribute much to the total error. There is some indication of a component due to males from the same line, but its relative magnitude renders it unimportant. In both fertiles and semisteriles, then, there is evidence of homogeneity among the various factors studied. The variance for the fertiles is about twice the variance for the semisteriles, but the respective average litter sizes are
8.4 and 3.5. In view of this relationship, it is quite possible that the variance is proportional to the mean litter size, at least in the range covered by this experiment.

\section{TABLE 5}

Variance Analyses Based on Litter sizes

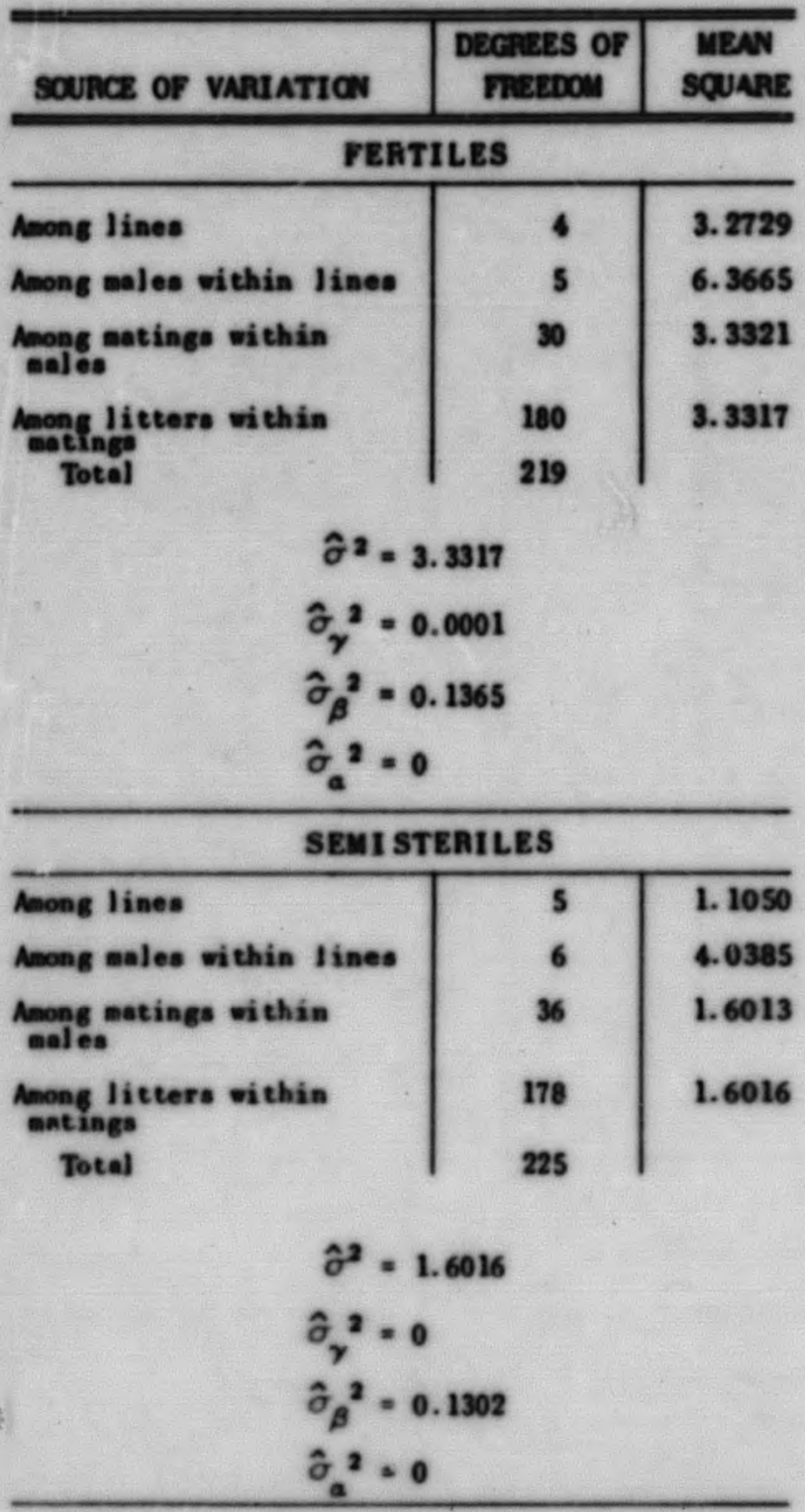


ANALYsis OP agCOHBINATION PERCENTAGES FOR SEVERAL EXPERIIENTS vITH BACEERIоримer та"

oriela. A. H. Doermann, Biology Division.

Participating weebers of Panel. A. W. Kimball and G. J. Atta.

Backeround and status. With bacteriophage T2H, a large number of experiments involving many different genetic crosses were performed. In each experiment the number of recombinants and the total number of phege perticles were counted. The total numbers ranged from 450 to 4300 , and the number of experiments per cross varied from one to nine. In some cases experiments from the same cross checked very well, and in other cases there was considerable divergence. An analysis of the average recombination percentages evaluated with respect to the crosses was desired.

Let $x_{i j}$ be the observed proportion in the $f_{\text {th }}$ experiment for the $i$ th cross $\left(i=1, \ldots, k_{j} ; j=1, \ldots, n_{i}\right)$. Further, let

$$
x_{i j}=p_{i}+p_{i j}+\epsilon_{i j} .
$$

where $P_{i}$ is the true average proportion for the $i$ th cross, $P_{i j}$ is the deviation of the $j$ th experiment from the true proportion for the $i$ th group caused by such extraneous factors as temperature, media, etc., and $\epsilon_{i j}$ is the usual binomial variation. $P_{i j}$ and $c_{i j}$ are assumed to have zero expectations and to be mutually independent so that

$$
\begin{aligned}
& \epsilon\left(x_{i j}-P_{i}\right)^{2}=V\left(p_{i j}\right)+V\left(\epsilon_{i j}\right) \\
& =\sigma_{i}^{2}+\frac{\left(p_{i}+p_{i j}\right)\left(1-p_{i}-P_{i j}\right)}{n_{i j}} .
\end{aligned}
$$

where $n_{i j}$ is the total number of particles counted in the $j$ th experi. ment of the $i$ th group, and $\sigma_{i}{ }^{2}$ represents the extrareous variation from experiment to experiment within a group. If weights are chosen equal to the reciprocal variances, the weight for $x_{i j}$ would be

$v_{i j}=\frac{1}{V\left(x_{i j}\right)}=\frac{n_{i j}}{n_{i j} \sigma_{i}^{2}+n_{i j}\left(1-n_{i j}\right)}$,

where $\eta_{i j}=p_{i}+p_{i j}$. If, further,

$$
\sigma_{b}^{2}=\frac{n_{i j}\left(1-n_{i j}\right)}{n_{i j}}
$$

then

$$
v_{i j}=\frac{1}{\sigma_{i}^{2}\left[1+\frac{\sigma_{b}^{2}}{\sigma_{i}^{2}}\right]}
$$

The least that can be expected is the computation of estimates of $\sigma_{b}^{2}$ and $\sigma_{i}{ }^{2}$ and the use of then to de. termine approximate weights. If a $\chi^{2}$ is computed for each cross in the usual fashion these $\chi^{2}$, s are pooled, it can be shown that

$$
\frac{E\left(\chi^{2} \text { pooled }\right)}{f}=1+\frac{\overline{\sigma_{i}^{2}}}{\overline{\sigma_{b}^{2}}} .
$$

where $f$ is the number of degrees of freedom for the pooled $\chi^{2}$ and

$$
\begin{gathered}
\overline{\sigma_{i}^{2}}=\sum_{i=1}^{k} \frac{\sigma_{i}^{2}}{k} . \\
\overline{\sigma_{b}^{2}}=E\left\{\frac{n_{i j}\left(1-n_{i j}\right)}{n_{i j}}\right\} .
\end{gathered}
$$




\section{MATHEMATICS PANEL QUARTERLY PROGRESS REPOAT}

From Eq. 1 an estimate of the percentage $a$ of the total variation that is due to extraneous variation can be obtained

$$
a=\frac{\frac{\chi^{2} \text { pooled }}{f}-1}{\frac{\chi^{2} \text { pooled }}{f}}
$$

For this type of problem, Cochran(4) gives the following set of rules for determining the kind of weights to use :

a.

wIGHTS

$>70 \%$
$<20 \%$

equal

between 20 and $70 \%$

binomial

exact or partial

In the present case, it was found that $\chi^{2}$ pooled $=153.26, f=69, a=55 \%$. Accordingly, it was decided that exact weights would be used.

For the exact weights more information is required. It can be shown that if $x_{i j}=a_{i j} / n_{i j}$.

$$
\frac{a_{i j}\left(n_{i j}-a_{i j}\right)}{n_{i j}\left(n_{i j}-1\right)}
$$

is an unbiesed estimate of $\pi_{i j}\left(1 \cdot \pi_{i j}\right)$. Since

$$
\overline{\sigma_{b}{ }^{2}}=E\left\{\frac{\pi_{i j}\left(1-\pi_{i j}\right)}{n_{i j}}\right\}
$$

an unbiased estimate of $\overline{\sigma_{b}{ }^{2}}$ is given by

$\hat{\sigma_{b}^{2}}=\left[\frac{1}{k \sum_{i} n_{i}}\right] \sum_{i, j}\left[\frac{a_{i j}\left(n_{i j}-a_{i j}\right)}{n_{i j}{ }^{2}\left(n_{i j}-1\right)}\right]$.

(4). 6. Coebrea, "Aacolyois of voriones for

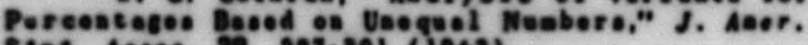
stot. Alove. 30.207 .301 (1943).
This estimate can then be used in conjunction with $\mathrm{Eq}$. 1 to provide an estimate of $a_{i}{ }^{2}$. In most cases, one estimate of $a_{i}{ }^{2}$ is sufficient, since $a_{i}{ }^{2}$ is approximately proportional to $P_{i}\left(1-P_{i}\right)$; and if $0.3<P_{i}<0.7$. there is very little variation among the $a_{i}{ }^{2}$. In the present set of experiments, however, several re. combination percentages are well below 0.3 , so that an estimate of $\sigma_{i}{ }^{2}$ was actually determined for each cross. Where only one experiment per cross was available, the over-all estimate $\sigma_{i}{ }^{2}$ was used.

One finel complication arose. In some experiments it was possible to identify only one-half the recombinants. These proportions had to be doubled to be comparable with the crosses in which all recombinants were identified. Ordinarily such a procedure would simply increase the variance by a factor of 4 , but since the final analyois of variance was based on transformed proportions, the effect on the variance had to be computed.

If $p$ is a bionomial variote with $E(p)=\pi$, then the variance of

$$
y=\sin ^{-1} \sqrt{p}
$$

is given approximately by

$$
\begin{aligned}
V(y) & =V(p)\left[\left(\frac{d y}{d p}\right)_{p=\pi}\right]^{2} . \\
& =\frac{\pi(1-\pi)}{n}\left[\frac{1}{2 \sqrt{\pi} \sqrt{1 \cdot \pi}}\right]^{2}, \\
& =\frac{1}{4 n} .
\end{aligned}
$$

Similerly, if $z=\sin ^{-1} \sqrt{2 p}$, 


$$
\begin{aligned}
V(z) & =V(p)\left[\left(\frac{d z}{d p}\right)_{p=n}\right]^{2}, \\
& =\frac{\pi(1 \cdot \pi)}{n}\left[\frac{1}{\sqrt{2 \pi} \sqrt{1 \cdot 2 \pi}}\right]^{2}, \\
& =\frac{1 \cdot \pi}{\frac{1}{2} \cdot \pi}\left(\frac{1}{4 n}\right) .
\end{aligned}
$$

Thus $V(z)$ exceeds $V(y)$ by efactor

$$
\frac{1 \cdot n}{\frac{1}{2} \cdot n}
$$

This means that the weights corresponding to proportions which heve been doubled wast be multiplied by the factor

$$
\frac{\frac{1}{2} \cdot \pi}{1 \cdot \pi}
$$

where $n$ is the observed proportion.

The weights determined in this fashion were used to compute weighted analysis of variance, and with the results it was possible to evaluate the differences among the recombination percentages for the several crosses. A paper containing the details of the experiment and the analysis has been prepared and will be subitted to an appropriate journal.

\section{DETERHNATI ON OF A PROBABILITY DISTRI -} BUTION FOA A GENETICS EXPEAIIENT

erieta. K. C. Atwood, Biolegy Division.

\section{Participatiag weaber of Panel.} A. W. Kimball.

Backeround and status. It is postulated that in aiploid organism two neighboring genes each have n compartments of equal size, as illustrated in Fig. 1. It is also assumed that one inctetion is induced inde. pendently in each gene and will appear at random in one of the compartments. The problem is to determine the probability distribution for the distance $x$ between the compartments containing the mutations. In particular, the mean and the variance of the distribution ore desired.

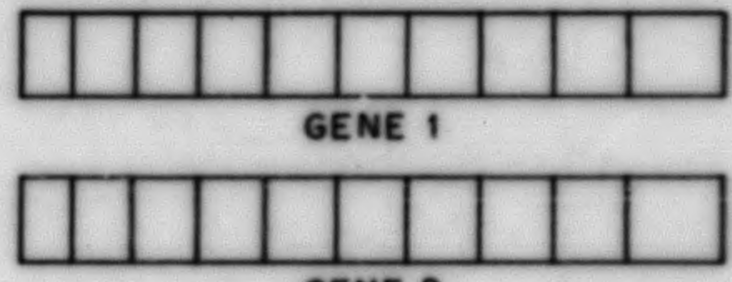

\section{GENE 2}

Fiz. I. n Cosparteents.

Clearly there are $n^{2}$ ways in which the event can happen. In order for $x$ to be zero, the mutations must occur is adjacent compartments. There are $n$ ways in which this can happen. By simple induction it can be shown that there are $2(n-x)$ ways in which the distance $x($ for $x>0)$ can be obtained. Thus,

Prob. $(x=0)=\frac{n}{n^{2}}=\frac{1}{n}$

and

$$
\text { Prob. }(x=a)=\frac{2(n-a)}{n^{2}}(a>0) \text {. }
$$

If these expressions are correct, the probabilities must add to one. Then

$$
\begin{aligned}
\frac{1}{n}+\sum_{-1}^{n-1} \frac{2(n-a)}{n^{2}} & =\frac{1}{n}+\frac{2}{n^{2}} \sum_{a=1}^{n-1}(n-a) \\
& =\frac{1}{n}+\frac{2}{n^{2}} \cdot \frac{n(n-1)}{2} . \\
& =1 .
\end{aligned}
$$

and the condition is satisfied. 


\section{mATHEMATICS PANEL GUARTERLY PROGRESS REPORT}

By definition the mean and variance of the distribution are given by

$$
\mu=\sum_{a=0}^{n-1} p_{e} x_{e} .
$$

$\sigma^{2}=\sum_{a=0}^{n} P_{a}\left(x_{a}-\mu\right)^{2}=\sum_{a=0}^{n+1} P_{a} x_{a}{ }^{2}-\mu^{2}$.

respectively, where

$$
x_{a}=a
$$

and

$$
\text { P. }=\text { Prob. }\left(x_{a}=a\right) \text {. }
$$

Hence,

$$
\begin{aligned}
\mu & =\sum_{n=1}^{n-1} \frac{2(n-a)}{n^{2}} a \\
& =\frac{2}{n^{2}}\left[n \sum_{a=1}^{n-1} a \cdot \sum_{n=1}^{n-1} a^{2}\right] \\
& =\frac{2}{n^{2}}\left[n \frac{n(n-1)}{n(n-1)(2 n \cdot 1)}\right. \\
& =\frac{n^{2} \cdot 1}{3 n} .
\end{aligned}
$$

Likewise,

$$
\begin{aligned}
\sigma^{2}= & \sum_{a=1}^{n-1} \frac{2(n-a)}{n^{2}} a^{2} \cdot \mu^{2}=\frac{2}{n^{2}}\left[n \sum_{a=1}^{n-1} a^{2}-\sum_{a=1}^{n-1} a^{3}\right] \cdot \mu^{2} \\
& =\frac{2}{n^{2}}\left[n \frac{n(n-1)(2 n-1)}{6}-\frac{n^{2}(n-1)^{2}}{4}\right] \cdot \mu^{2}=\frac{\left(n^{2}-1\right)\left(n^{2}+2\right)}{18 n^{2}} .
\end{aligned}
$$

For large $n$, the coefficient of variation $\sigma / \mu$ is approximately $1 / \sqrt{2}$ or abote $71 \%$.

\section{IRRADIATION EFFECT ON CELL EXTINCTION}

oriein. M. E. Gaulden, Biology Division.

\section{Participating meebers of Panel.}

J. Moshanan and G. J. Atto.

References. Mathenatics Panel Quarterly Progress Report3, ORNL-1151, 1091, and 1029.

Background and status. Previous experiments have revealed a highly significant effect of the presence of heat on the cell extinctions. In the present experiment, 25 grasshopper cells were subjected to dose of $12,000 \mathrm{r}$ of $\mathrm{x}$ irradiation. These cells were matched against 25 control cells that received no irradiation. All cells were stained with methyl green and cell extinctions, $E$, were measured by the formula

$E=\frac{C^{2} R^{3}}{R^{3} \cdot\left(R^{2}-C^{2}\right)^{3 / 2}}\left[\log _{10} I_{0} \cdot \log _{10} I_{n}\right]$. where

$$
\begin{aligned}
& C=\text { aperature radius of the lens: } \\
& R=\text { radius of cell nucleus, } \\
& I_{0}=\text { light absorption of background, } \\
& I_{n}=\text { light absorption of nucleus. }
\end{aligned}
$$


On the basis of a pooled variance estimate, a test revesled that there was no significant $(P>0.10)$ dif ference between the treated mean $\left(\bar{E}_{t}=0.903\right)$ and the control mean $\left(\bar{E}_{e}=1.045\right)$. Ninety-five per cent confidence limits for the treated mean are $(0.507,1.299)$ and for the control mean $(0.603,1.487)$.

\section{A PRoblei IN MIXING}

origin. A. J. Weinberger, Chemistry Division.

\section{Participating weaber of Panel.}

J. Moshman.

Background and status. A volume of a given material, tagged with some radioactive molecules, is fed into a mixing tank of known volume, exchanging with the contents of the tank. Assuming that the tank is full, the fraction of radioactive molecules in the tank when given amount of the material is entering it is determined by

$$
d f_{v}^{*}=\frac{d n^{*} \cdot f_{v}^{*} d n}{V}
$$

where

$$
\begin{aligned}
f_{*}^{*}= & \text { the fraction of radioactive } \\
& \text { moles in the tank, } \\
n^{*}= & \text { the number of tadioactive } \\
& \text { moles entering the tank, } \\
n= & \text { the total number of moles } \\
& \text { entering and hence leaving } \\
& \text { the tank, } \\
v= & \text { the volume of the tank in } \\
& \text { moles. }
\end{aligned}
$$

Now

$$
n^{*}=n^{k \cdot / k} \text {. }
$$

where

$$
0 \leqq k \cdot \leqq k
$$

Letting

$$
a=\frac{k}{k} \text {. }
$$

then

$$
0 \leqq a \leqq 1 \text {. }
$$

From Eqs, 2 and 3, it is determined that

$$
d n *=a n^{e-1} d n \text { : }
$$

and substituting in Eq. 1 ,

$$
d f_{v}^{*}=\frac{\left[a n^{* * 1} \cdot f_{v}^{*}\right] d n}{V} .
$$

for which the solution is

$$
f_{v}^{*}(n) e^{n / v}=f_{v}^{*}(0)
$$

$$
+\frac{a}{v} \int_{0}^{n} n^{a \cdot 1} e^{n / v} d n
$$

The integral in Eq. 5 would be an incomplete $\Gamma$-function if $a-1>0$, but this is not so. then

If $a=1$ in the integrand of Eq. 5 ,

$$
f_{v}{ }^{*}(n) e^{n / v}=f_{v} \cdot(0)+a e^{n / v} .
$$
then

If $a=0$ in the integrand of Eq. 5 ,

$$
f_{v} \cdot(n) e^{n / v}=f_{v}^{*}(0)
$$

$$
+\frac{a}{V}\left[E_{i}(n)-E_{i}(0)\right] \text {, }
$$


where

$$
E i(x)=\int_{-\infty}^{s} \frac{e^{t}}{t} d t
$$

which may be found in Jahnke and Emde's Funktionentafeln.

Then

$$
\begin{aligned}
& f_{v} \cdot(0)+\frac{a}{v}[E i(n)-E i(0)] \leqq f_{v}^{*}(n) \\
& \leqq f_{v}^{*}(0)+a e^{n / v} .
\end{aligned}
$$

KINETICS OF THE HBro, REACTION

origin. O. E. Myers, Chemistry Division.

Participating menbers of Panel. J. H. Fishel and C. L. Perry.

Reference. Mathematics Panel Quarterly Progress Report, ORNL-1151.

Background and status. The numerical integration of the systems of nonlinear differential equations described in the previous report has been continued. Whitehurst of Arnold Research Organization. Inc. will use this system of differential equations as a test problem for the Arnold Research Organization MADDIDA. The numerical integration using IBM comput . ing machines will be continued next quarter.

ION PRODUCtION IN AN IONIZATION CHAMBER

orisin. M. Slater and H. H. Ritchie. Health Physics Division.

Participating nembers of Panel.

J. H. Fishel and C. L. Perry.

Background and status. The transcendental function

$$
X(x, y)=\int_{0}^{x} \frac{\theta}{\cos \theta} e^{-(\theta / y)^{2}} d \theta
$$

was used in a theoretical evaluation of the ionization current produced in an ionization chamber by electrons scatered from a foil. $X$ is now being tabulated for the grid

$$
x=\frac{5 \pi}{18}\left(\frac{\pi}{18}\right) \frac{8 \pi}{18}
$$

and

$$
y=\frac{\pi}{12}\left(\frac{\pi}{12}\right) \pi
$$

The tabulation will be completed early in the next auarter.

EVALUATION OF THE LATERAL DISTEIBUTION OF ENERGY DISSIPATED BY A mOVING ION

origin. J. Neufeld and $W . S$. Snyder, Health Physics Division.

Participating meabers of Panel. V. C. Carlock and K. P. Graw.

Background and status. Calculations were performed for the determination of the energy loss per centimeter of path of an ion traveling in a homo. geneous medium because of the inter. action of the ion with particles of the medium at a distance $x$ from the path of the ion. The mediums were hydrogen, carbon, nitrogen, oxygen, and tissue. The energy loss was tabulated as a function of energy and distance $x$. This project was completed.

\section{MONTE CARLO ESTIMATE OF COLLISION} DIstRIBUTIONS IN TISSUE

origin. W. S. Snyder and J. Neufeld, Health Physics Division.

Participating mebbers of panel. K. P. Graw and C. L. Perry. 
Beferences. Mathenatics Panel Quarterly Progress Reports, ORNL-345. $408,561,634,726,818,888,979$. 1029, 1091, and 1151 .

Beckeround and status. The computations and tabulations for this problem were completed during the quarter. The use of the Monte Carlo neutron histories to simulate an isotropic source is being considered.

\section{AMPLIFIER RESPONSE TO PROPORTIONAL counter pulses}

origin. G. S. Hurst, Health Physics Division.

Participating wenber of Panel. C. Perhacs.

Reference. Mathenatics Panel Quarterly Progress Report, ORNI-1151.

status. The computations started last quarter have been completed.

\section{X-ray CRYstal. anaLYsis}

oriein. G. P. Smith, Jr., Metallurgy Division.

\section{Participating weaber of Panel.} J. H. Fishel.

Beference. Watheatics Panel Quarterly Progress Report, ORNL-1151.

Background and status. The computacions described in the previous report were completed in November.

\section{FERHI FUNCTIONS}

oriein. M. E. Bose and P. B. Bell. Physica Division.

Participating weabers of Panel. C. L. Perry and N. M. Dismuke. status. A table of $P_{0}(p, z)$ was issued as ORNL-1222. (s) The tabulated function was defined as follows:

$$
\varphi_{0}(p, z)=\frac{1+s_{0}}{2} \frac{p}{6} F_{0}(p, z),
$$

where

$F_{0}(p, z)$

$$
=4\left(2 p r_{0}\right)^{2\left(0_{0}-1\right)} e^{n y} \frac{\left|\Gamma\left(s_{0}+i y\right)\right|^{2}}{\Gamma^{2}\left(2 s_{0}+1\right)} \text {. }
$$

$$
\begin{aligned}
& s_{0}=\sqrt{1 \div a^{2} z^{2}}, \\
& y=a z \frac{w}{p}, \\
& p=\sqrt{w^{2} \cdot 1} \geq 0, \\
& r_{0}=\frac{1}{2} a A^{1 / 3}, \\
& a=\frac{1}{137.03} .
\end{aligned}
$$

Table values were compared and found to agree with results obtained by $E$. Greuling and by the Bureau of Standards.

CALCULATION OF INTERNAL ConveRsion COEFFICIENTS eITU SCREENING

\section{Division.}

eriein. M. E. Rose, Physícs Participating wesber of Panel. M. R. Arnette.

(5) N. Diseabe, C. L. Perry, W. E, Alene, and

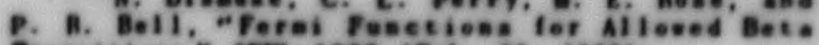
Transitions," obll-1222 (Feb, 22, 1952). 


\section{MATHEMATICS PANEL QUARTERLY PROGRESS REPORT}

Reference. Mathenatics Panel Quarterly Progress Report, ORNL-1151.

status. The coding of the problem for the SEAC and checking of the code on the SEAC has been continued. It is now predicted that the coding and computation will be completed during. the next querter.

CaLculation of RACAI coEfFicients pon THE ANGULAB DISTRIBUTION IN NUCLEAB REACTIONS

origin. M. E. Rose and L. C. Biedentarn, Physics Division.

Partic a ating meabers of Panel. S. L. Hu $t$, nd V. C. Carlock.

Referears. Physics Division Quarterly Progress Report, ORNL-1005, Mathematics Panel Quarterly Progress Reports, ORNI-1029, 1091, and 1151.

Background and status. The computations described in the previous reports have been completed and checked. The values of $w\left(l, l_{1}, l_{2}\right.$, $j_{2} ; 4 L$ ) are now being calculated. In addition, tables containing four decimal digit approximations to W $\left(I_{1}, J_{1}, I_{2}, J_{3}, L\right)$ are being prepared for pabfication in a physics journal.

\section{BETa oEcay (Field Facters)}

origin. M. E. Rose and P. R. Bell, Physies Division.

Participating meabers of Panel. C. I. Perry, V. A. Hoyle and N. M. Di smuke.

status. The approximations used to compute the field factors L, M, N(6) were found to be invalid for part of the ranges of the independent variables $p$ and $z$. These calculations will therefore be repeated using valid approximations. Plans at present are to perform the calculations on the MIT Whirlwind. Coding of the problem for this computer is in progress. In addition to $L, M, N$, the factors $P, Q$, $R^{(0)}$ will be tabulated.

\section{ESTIMATION OF ERROR AND COUNTING} PERIODS IN A PILE EXPERIMENT

origin. M. K. Hullings, Physics Division.

Participating menber of Panel. A. W. Kimball.

Background and status. In one pile experiment four neutron counts are taken under different experimental conditions and combined to provide one statistic. Let $x_{1}$ and $x_{2}$ be the total counts with the shutter open and closed, respectively, under the first condition, and let $y_{1}$ and $y_{2}$ be the corresponding total counts under the second condition. Further, let $t_{x_{1}}, t_{x_{2}}, t_{y_{1}}$, and $t_{y_{2}}$ be the counting periods in minutes. Óne problem is to find the variance of

$$
R=\frac{\bar{x}_{1} \cdot \bar{x}_{2}}{\bar{y}_{1} \cdot \bar{y}_{2}}
$$

where the bar notation is used to indicate counts per minute (e.g., $\left.\bar{x}_{1}=x_{1} / t_{x_{1}}\right)$. The second problem is to find some method of estimating optimum counting periods.

The exact probability distribution of $R$ cannot be obtained in workable form. An approximate variance for $R$ (6) D. L. Puraey, "Interaction of the Theesp of
Beta Deeay," Phit. Uag. 42. $1206(1951)$. 
may be computed by means of the socalled "delta" method described in ORNL-1029. $(7)$ In general

$V\left(\frac{x}{y}\right) \cong\left(\frac{\mu}{\nu}\right)^{2}\left[\frac{V(x)}{\mu^{2}}\right.$

$$
\left.+\frac{V(y)}{\nu^{2}} \cdot 2 \frac{\operatorname{cov}(x, y)}{\mu \nu}\right] .
$$

where $\mu=E(x), \nu=E(y)$. If $x$ and $y$ are independent, the last term in the brackets vanishes. In practice $\mu$ and $\nu$ are replaced by their sample esti. mates.

In the present problem $x=\bar{x}_{1}-\bar{x}_{2}$ and $y=\bar{y}_{1}-\bar{y}_{2}$. Since $\bar{x}_{1}$ is a sample mean from a Poisson distribution and the variance of a Poisson distribution is equal to the mean, an estimate of the variance of $\bar{x}_{1}$ is given by $\bar{x}_{1} / t_{x_{1}}$. Variance estimates for $\bar{x}_{2}, \bar{y}_{1}$, and $\bar{y}_{2}$ are obtained in a similar fáshion. Since $x$ and $y$ are independent, from Eq. 1 there is obtained

$v\left(\frac{x}{y}\right) \cong\left(\frac{x}{y}\right)^{2}\left[\frac{\bar{x}_{1}+\frac{\bar{x}_{2}}{t_{1}}}{x^{2}}\right.$

$$
\left.+\frac{\frac{\bar{y}_{1}}{t y_{1}}+\frac{\bar{y}_{2}}{t y_{2}}}{y^{2}}\right]
$$

which is based on the weIl-known theorem that the variance of the difference of two independent random

(7) Watheantics Panel Quarterly Progress Aeport for the Period Ending Aprit 30 , 1951. OANL- 1029. p. 2 . variables is the sum of the separate variances.

The problem of determining optimum counting periods is also complicated by the fact that the distribution of $R$ is available only in integral form. A rough method for determining count. ing periods can be obtained, however, by incorporating certain restrictions on the respective components of error. If it is required that $x$ and $y$ have the same absolute error, it is neces. sary that

$$
\frac{\bar{x}_{1}}{t_{x_{1}}}+\frac{\bar{x}_{2}}{t_{x_{2}}}=\frac{\bar{y}_{1}}{t_{y_{1}}}+\frac{\bar{y}_{2}}{t_{y_{2}}}=k .
$$

If it is required further that open and closed shutter readings have the same absolute error, then

$$
\frac{\bar{x}_{1}}{t_{x_{1}}}=\frac{\bar{x}_{2}}{t_{x_{2}}} \text { and } \frac{\bar{y}_{1}}{t_{y_{1}}}=\frac{\overline{y_{2}}}{t_{y_{2}}} \text {. }
$$

From Eqs, 3 and 4 the following relations can be derived:

$$
\begin{array}{ll}
t_{x_{1}}=\frac{2 \bar{x}_{1}}{k}, & t_{y_{1}}=\frac{2 \bar{y}_{1}}{k} . \\
t_{x_{2}}=\frac{2 \bar{x}_{2}}{k}, & t_{y_{2}}=\frac{2 \bar{y}_{2}}{k} .
\end{array}
$$

If the specified error in $x / y$ is $\epsilon$, $k$ may be computed from Eq. 2 by placing

$$
V\left(\frac{x}{y}\right)=\epsilon^{2}
$$




\section{MATHEMATICS PANEL QUARTERLY PROGRESS REPORT}

and solving for $k$. This gives

$$
k=\frac{\epsilon^{2}}{\left(\frac{x}{y}\right)^{2}\left[\frac{1}{x^{2}}+\frac{1}{y^{2}}\right]}
$$

Once $k$ is estimated, estimates of the counting periods may be obtained from Eq. 5 .

It should be noted that preliminary estimates of $x$ and $y$ are needed in order to compute $k$. Frequently these may be available from previous experi- ments or from short trial runs in the experiment under consideration.

\section{Calibration of a calorimeter}

origin. J. B. Trice and A. B. Lewis, Solid State Division.

Participating menber of Panel. N. D. Given.

Bacliground and status. The experimental values of the temperatures inside and outside alorimeter as functions of time were smoothed, differenced, differentiated, and graphed. This project was completed. 
PERIOD ENDING JANUARY 31, 1952

\section{PROJECTS}

DETERIINATION OF FAST NEUTRON FLUX IN X-10 capaite pILE

oriein. D. K. Holmes, Physics Division.

Participating nembers of Panel. J. Moshman and G. J. Atta; E. B. Carter, Central Statistical Laboratory, K-25.

Background and status. The IBM procedure for the Monte Carlo calcu. lations of neutron histories has been perfected and histories are being calculated.

To estimate the flux in a given region Fig. 2 may be considered. Of interest is the flux through the small cylinder of cross-sectional area $A$ and height $\delta t$. The jagged $l$ ine represents the reflection of the flight path of the $i$ th neutron in the $z-y$ plane; all neutrons are arbitrarily started at $z=0$. If the starting point of the path were in the interval $\left(z_{i}, z_{i}\right)$, the neutron would have contributed to the flux through the cylinder of volume
St A. The flux $\phi$ is then proportional to

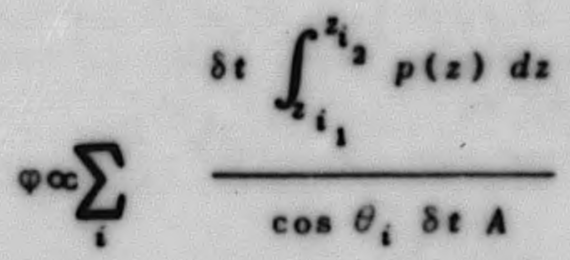

where $\theta_{i}$ is the angle of incidence of the path with the cylinder and $p(z) d z$ is the probability of a neutron originating in the interval $(z, z+d z)$.

Now

$$
p(z)=\frac{\pi}{2 L} \cos \left(\frac{\pi z}{L}\right)
$$

and

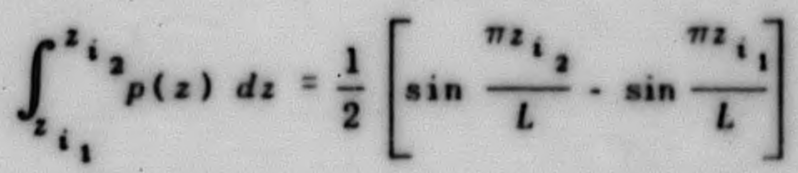

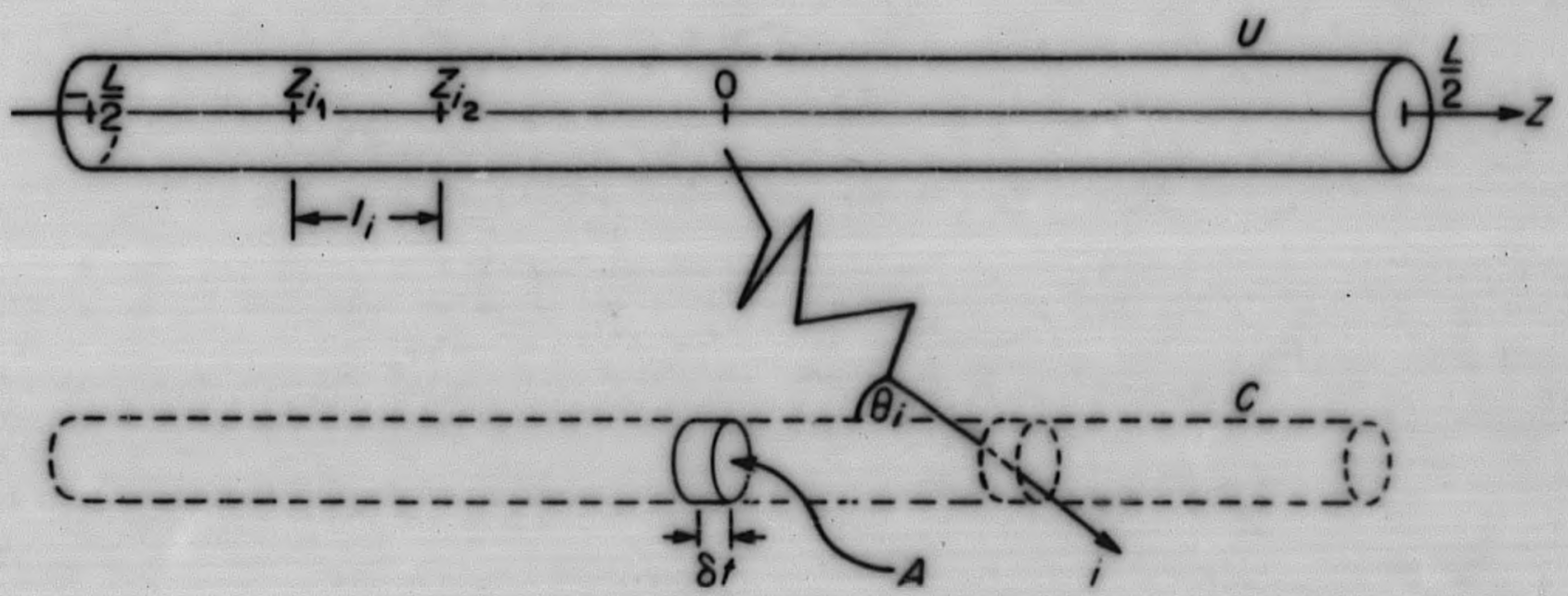

Fig. 2. Flux in a given Region. 


\section{MATUEMATICS PANEL QUARTERLY PROGRESS REPORT}

let

$$
z_{i_{2}}=z_{i_{1}}+t_{i} .
$$

where $t$ is the reflection of the actual flight path through the cylinder $C$ along the $z$ axis. Then, by dropping subscripts, where $p$ is the actual path length in the cylinder $C$.

The effect of the approximations given above are being investigated to establish statistical estimates of the average error in view of the distri. butions of $x, P$, and $\theta$.

$$
\frac{1}{2} \sin \left[\frac{\pi z_{i_{2}}}{L} \cdot \sin \frac{\pi z_{i}}{L}\right]=\frac{1}{2}\left[\sin \frac{\pi\left(z_{i_{1}}+l_{i}\right)}{L} \cdot \sin \frac{\pi z_{i}}{L}\right]
$$

$$
=\frac{1}{2}\left[\sin \frac{\pi z}{L} \cos \frac{\pi l}{L}+\cos \frac{\pi z}{L} \sin \frac{\pi l}{L} \cdot \sin \frac{\pi z}{L}\right]=N .
$$

If $N$ were to be estimated by

$$
\frac{\pi l}{2 L} \cos \frac{n z}{L}=\tilde{N} .
$$

then the error would be

$$
\begin{aligned}
E=N \cdot \tilde{N}= & \frac{1}{2}\left\{\sin \frac{n z}{L}\left(\cos \frac{\pi l}{L} \cdot 1\right)\right. \\
& \left.+\cos \frac{n z}{L}\left(\sin \frac{\pi l}{L} \cdot \frac{n l}{L}\right)\right\} .
\end{aligned}
$$

But if $(l / L)<<1, \cos (\pi l / L) \sim 1$, and the sin $(n l / L)$ may be replaced by the angle. By assuming $N$ as the numerator, then

$\oplus \propto \sum \frac{\frac{n l}{2 L} \cos \frac{\pi z}{L}}{\cos \theta A}=\sum \frac{P}{A} \frac{n}{2 L} \cos \frac{\pi z}{L}$.

\section{KINETICS OF HEE}

origin. T. A. Welton, Physics Division, HRP.

Participating meabers of Panel. N. D. Given and W. C. Sangren.

Beferences. Mathenatics Panel Quarterly Progress Report, ORNL-1151. and Hoageneous Reactor Project Quarterly Progress Report, OPNL-1221.

Backeround and status. In the reports indicated in the references, the set of nonlinear differential equations that are thought to represent the kinetics of the HRE have been presented. In these reports two general methods of obtaining approximate solutions are noted, one of which uses numerical integration and the other analytical techniques. The systems, which were numerically integrated by the SEAC, have now been analyzed. Additional analytical 
techniques have been used and various short and iterative formulas been developed. The results of the formulas have been compared with the SEAC results. A separate report will contain the results of this investigation.

\section{CIRCULATIEN IN BOILING REACTORS}

oriein. P. C. Zmola, Reactor Experimental Engineering Division.

Participating webber of Panel. E. N. Lawson.

Background and status. By using formulas derived by P. C. Zmola. various I umped variables are being calculated and graphed.

INVESTIGATION OF SOLUTIONS OF THE BoLtzmanN EQUATION Fon THE DIFFUSION OF NEUTRONS

orieia. W. K. Ergen, Reactor Physics Division, ANP.

Participatiag meaber of Panel. N. Edmonson.

Background and status. It is possible to obtain solutions of the Fermi age diffusion equation under some conditions. There has occurred the auestion: Is it possible to construct a mode of solving the Boltzmann equation under these conditions by utilizing the sclutions of the age diffusion equation as initial values? This investigation has just started.

A MULTIGROUP METHed FoR computing THE NEUTRON DISTRIBUTION IN A CVLINDRICAL. REACTOR WITH REFLECTED CONVEX SURFACE ANB BARE ENDS

origin. N. M, Smith, Reactor Physies Division, ANP.
Participating webber of Panel.

N. Edmonson.

Background and status. Trial computations are now being set up by Y-12 IBM group.

KINETICS OF INTERMEDIATE AND LARGE mOHOGENFOUS REACTORS

erigin. R. B. Briggs, Research Director's Division.

Participating nesbers of Panel. N. D. Given and w. C. Sangren.

Backeround and status. The short and iterative formulas, which were developed for finding power and pressure maximums under step changes in reactivity for the HAE have been used to find power and pressure maxi mums for larger homogeneous reactors. The results were graphed and submitted te A. B. Briggs .

TEO-GROUP THRE -REGION COMPUTATIONS Fon A PReDUCTION REACTOR

origin. J. A. Parks, Long Range Planning Group.

Participating menber of Panel. H. B. Goertzel and V. S. Carlock.

Backeraund and status. The caleulations by matrix methods of the core multiplication constant, the radial buckling constant, and fast and slow neutron fluxes and currents for four reactor designs have been started. The calculations will be completed during the next quarter.

\section{OPERATIJNS GRENHOUSE}

Project 1. Toenty-eight Day Lethality study.

origin. G. V. Leroy, University of Chicago, U. S. Navy Task Force 3. 


\section{MATHEMATICS PANEL OUARTERLY PROGRESS REPOAT}

Participating weabers of Panel. J. Moshman and G. J. Atta.

Backeround and status. Previous studies (ORNL-1151) indicated the possibility of an age effect on the median lethal dose of the mice at stations 70 and 71 for the Easy shot. To investigate this apparent phenomenon further, the original data were broken down by age within weight groups. The slopes and LD, sere computed and are reproduced in Tables 6 and 7 .

\section{TABL.E 6}

Wedian Lethal Doses of Greenhouse aice stations 70 and 71

\begin{tabular}{|c|c|c|c|c|c|}
\hline \multirow[b]{3}{*}{$\begin{array}{c}\text { weIGT } \\
\text { (e) }\end{array}$} & \multicolumn{5}{|c|}{ ACE (neeks) } \\
\hline & 8 & 9 & 10 & 11 & 12 \\
\hline & \multicolumn{5}{|c|}{$\mathrm{U}_{\mathrm{se}}$} \\
\hline 15- 19 & 749.95 & 755.96 & 771.11 & 763.40 & 750.74 \\
\hline $20-24$ & 730. 39 & 755.85 & 743. 10 & 754. 16 & 757.72 \\
\hline $25-29$ & 757.73 & 743.88 & 752.66 & 756.69 & 771.24 \\
\hline
\end{tabular}

TABLE 7

SI opes of Dose-Response Curves for Greenheuse wice stations 70 aad 71

\begin{tabular}{|c|c|c|c|c|c|}
\hline \multirow[b]{3}{*}{$\begin{array}{l}\text { WEIGar } \\
\text { (E) }\end{array}$} & \multicolumn{5}{|c|}{ AGE (weekn) } \\
\hline & 8 & 9 & 10 & II & 12 \\
\hline & \multicolumn{5}{|c|}{ SLCPES } \\
\hline 15. 19 & 002042 & 0.01880 & 0.01723 & 0.02415 & 0.01612 \\
\hline $20-24$ & 0.02004 & 0.01914 & 0.01413 & 0.01442 & 0.01625 \\
\hline $25-29$ & 0.01410 & 0.01643 & 0.01221 & 0.01316 & 0.01641 \\
\hline
\end{tabular}

Subsequent analysis revealed no significant regression between nor. tality or slope on age within the various weight groups.

Previously reported $(\bullet)$ provioional I Dso and lopes may be taken as final with the exception of tray 3 . The LD, should read 749.50 instead of 760.22 , and the slope should be 0.01295 ineteed of the reported 0,01081 .

Project 2. Depigaentation study.

oriein. A. C. Upton, Biology Division.

Participating wenber of Panel. J. Moshman.

Background and status. Among the Greenhouse mice a marked depigmentation effect has been observed. The mouse hairs vory in color from the original dark glossy brown to a pronounced white. A quantification procedure was adopted that grades the degree of depigmentation from 0 (original brown) to 4 (all white) at six selected parts of the anatomy. Some of the sice are heing periodically observed and graded.

Analysis of the existing data is under way to determine the effective. ness of differentiated depigmentation as a discriminant of dose received and its possible use as a bivlogical dosimeter.

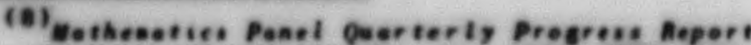
for the Period Endine Oetober 31. Tesi. onem-ilist. Table ?, : 23. 
PERIOD ENDING JANUARY 31, 1952

\section{PENDING PROBLEMS}

(Unclassified)

THRESHOLD vaLUES OF THE ANGULAR coRRELATION COEFFICIENTS

Orisin. M. E. Rose and G. B. Arfken, Physics Division.

MEAN FEEE PATH FOR FISSION SPECTRUn NEUTRONS

orieia. 1. C. Noderer, Physics Division.

INTERPOLATED VALUES OF THE INTERNAL. CONVERSION COEFFICIENTS wITH SCREENING eris in. Division.

M. E. Rose, Physics

\section{eFficiency of a ceYstal. (OFf-Axis Calculation)}

oriein. P. A. Bell, Physics Division.

\section{LAmB SHIFT}

oriein. T. A. Welton, Physics Division.

Calculation for counten conftoence L. InI Ts

$$
\text { Panel. }
$$

G. E. Albert, Mathematics

NUEERICAL EVALUATION OF TRIGONOHETRIC SERIES
oriein.
P. S. Borie, Metallurgy 
